\title{
Macroecology and Invasion Biology
}

Tim M. Blackburn

Department of Genetics, Evolution \& Environment, Centre for Biodiversity \& Environment Research, UCL, Gower Street, London WC1E 6BT, UK, and Institute of Zoology, Zoological Society of London, Regent's Park, London, NW1 4RY, UK

Tel: +44 (0) 203108 7694; Email: t.blackburn@ucl.ac.uk

Running head: Macroecology and invasion biology 


\section{Macroecology}

In 1988, my D.Phil. supervisor Paul Harvey came into my office to show me a recent paper from the journal American Naturalist. Evolution of species assemblages: effects of energetic constraints and species dynamics on the diversification of the American avifauna by Jim Brown and Brian Maurer was at best tangential to my thesis work on life history evolution, but Paul had an idea for a side project I could pursue testing for sampling effects in the relationship between abundance and body size in that assemblage (and others). I remember it taking me ages to grasp the concepts involved, I'm sure driving Paul's post-doc Mark Pagel almost to distraction with my failure to understand his explanations. However, I got it in the end, and the resulting paper (Blackburn et al., 1990) was not only my first ever publication, but also the start of more than a decade of research into the nascent field of macroecology. I started my doctorate with an active dislike of ecology, but ended up as an ecologist.

From that first foray into macroecology, a consistent theme of my research was the importance of considering the null hypothesis, and the implications of potential biases in the data analysed for that hypothesis. As the study of large-scale patterns in the abundance and distribution of organisms, macroecology was (and still is) largely based on the analysis of features expressed across large assemblages of organisms, and therefore not readily amenable to study through manipulative experiments. Attempts to infer process on the basis of natural experiments lacking controls require extra care to ensure that the patterns observed are not a consequence of sampling effects, or phylogenetic or spatial autocorrelation. For example, Brown \& Maurer (1987) had found a generally negative association between estimates of mean population density and body mass in North American breeding birds, but with the highest densities for species of intermediate mass. They suggested that the energetic demands of being a very small bird requires such species to feed on concentrated energy sources, which are in relatively short supply in the environment. These smallest birds therefore cannot maintain high population densities. Blackburn et al. (1990) explored the alternative hypothesis that the peak in population densities at intermediate masses was a sampling effect: if density was unrelated to mass, by chance alone we would expect the highest densities to be associated with the size classes with most species. These were intermediate size classes. The first hypothesis to be addressed in any 
study ideally should be the null, but what the null expectation was for macroecological patterns was not always obvious.

\section{Invasion Biology}

In 1998 a first visit to New Zealand to work on questions of extinction with Richard Duncan sparked a new interest in alien species. Growing up in the U.K. I was naturally aware of aliens, especially the birds (and whether or not they were "tickable"), but had taken the presence and status of such species for granted. It was not until I saw how abundant European thrushes, finches, and other passerines were on the Canterbury Plains - familiar British bird species dramatically out of range - that I realised just how interesting aliens might be to study. I was not alone in this conclusion: the literature on alien species had started to burgeon following the SCOPE (Scientific Committee on Problems of the Environment) programme on this topic initiated in 1982 (Williamson et al., 1986; Drake et al., 1989). Exploring this literature, it became clear that the approaches to answering questions about ecological systems developed by macroecologists were potentially useful for answering questions about aliens and their invasions. Macroecology and invasion biology share some important similarities.

First, like macroecology, much of the data analysed in invasion biology comes from large-scale natural experiments - more accurately "experiments in nature", since these are changes to the environment caused by humans (Diamond, 1986) - where controls are lacking. These experiments have involved the unplanned (in experimental terms) translocation and introduction of large numbers of individuals of animals, plants, and other taxa to areas beyond the natural limits of their geographic distributions (Richardson et al., 2011), over much of the course of human history. The lack of controls means that these experiments in nature need to be interpreted with caution, but they are useful sources of information for formulating and testing hypotheses for the causes and consequences of biological invasions (Richardson et al., 2004), and should not be dismissed as an inferior approach. Controlled, manipulative experiments are powerful for testing scientific hypotheses, but the inevitably limited spatial and temporal scales of these manipulations means that they may lack realism in situations, like biological invasions, where important system drivers operate over large areas and long periods of time (Diamond, 1986; Blackburn, 2004). 
Second, because experiments in nature are uncontrolled and unreplicated, much biological invasion data suffer from a similar range of biases to those encountered in macroecology. In particular, alien species are a non-random selection of native species (Lockwood, 1999; Tingley et al., 2010; Blackburn et al., 2017). For example, bird species with alien populations tend to be drawn from certain bird taxa, especially Galliformes, Anseriformes, Psittaciformes and Passeriformes, and from certain biogeographic regions (Blackburn \& Duncan, 2001b; Dyer et al., 2017). They also tend to be more widespread and abundant in their native ranges, larger-bodied and larger-brained, and more generalist in habitat use or diet (Blackburn et al., 2009; Sol et al., 2012). It is important to realise that these traits may not be the causes of success as an alien, but rather a consequence of the taxonomic and geographic biases: this realisation was slow to permeate macroecology (Blackburn \& Gaston, 1998; Blackburn, 2004), and was similarly not yet widespread in invasion biology around the turn of the Millennium (Blackburn \& Duncan, 2001a,b). Now, however, it is standard practice to use methods that account for phylogenetic and/or spatial autocorrelation when analysing variation in outcomes along the invasion pathway.

Third, as in macroecology, defining the appropriate null hypothesis for the question being addressed has not always received the attention it deserved in invasion biology (van Kleunen et al., 2010). This is especially problematic because invasion is not a unitary process, but instead a series of stages through which a species has to pass to go from native to alien invader (Williamson \& Brown, 1986; Williamson, 1996; Kolar \& Lodge, 2001; Blackburn et al., 2011). For example, some early studies attempted to identify the characteristics of alien species by comparing their traits to species without alien populations. Thus, Goodwin et al. (1999) compared characteristics of congeneric pairs of European plant species that had or had not established alien populations in New Brunswick, Canada. They found that the life history traits they analysed (lifeform, stem height, flowering period) did not distinguish between species with or without alien populations, but that native geographic range size did. However, this test does not tell us whether aliens differ because species with certain traits are more likely to have been introduced to new areas, or because species with certain traits are more likely to establish populations once there (Kolar \& Lodge, 2001). Native geographic range size is perhaps more likely to determine the former. In this context, Cassey et al. (2004) 
used parrots as a case study to show how our understanding of the invasion process depends on the comparison made. Parrot species with established alien populations tend to have larger native population sizes, and are more likely to exhibit sexual plumage dichromatism, than parrots without established alien populations. However, these differences arise because these are the characteristics of parrot species chosen for introduction: neither large population size nor sexual plumage dichromatism distinguishes whether introduced parrot species are more likely to succeed or fail in establishing. These distinctions matter. With the wrong analysis, it would be easy to conclude that there is little risk of species with small native ranges or population sizes establishing alien populations if introduced, when in fact these characteristics only affect the likelihood of being introduced in the first instance.

It seems to me that the implications of applying these insights from macroecology to invasion biology has been a shift in focus from natural to anthropogenic drivers in explaining the invasion process. The SCOPE programme on invasions (Williamson et al., 1986) identified two key questions concerning the invasion process - what factors determine whether a species becomes an invader or not? and what site properties determine whether an ecological system will resist or be prone to invasions? However, there is a missing third, key question - how are invasions affected by what humans do? Attention to null hypotheses in the light of the invasion pathway emphasises that outcomes in later pathway stages depend substantially on drivers at earlier stages, where human activities are especially important. Thus, which species are entrained in transport, and which transported species subsequently make it into the novel environment, both combine to constrain the identities and characteristics of species given the opportunity to become aliens. Likewise, human-mediated transport and introduction of species dictates the characteristics of the environments to which those potential aliens are exposed, and hence which environments are likely to suffer more or fewer invasions. Humans also modify features of the introduction of given species to given locations, most notably through the number of individuals introduced (propagule pressure), which is now recognised as a key driver of the establishment process (Lockwood et al., 2005; Simberloff, 2009; Cassey et al., 2018). Features of the species and environment obviously influence alien identities and locations, but in the context of anthropogenic activities. Methods that account for autocorrelation in outcomes have also influenced this shift by moderating the effects of those species and locations that dominate catalogues of invasions, and whose characteristics as a 
result had undue influence on analyses of invasion drivers. For example, islands have traditionally been seen as more susceptible to invasions (Elton, 1958), but good evidence for this is more difficult to find when controlling for non-independence in data (Sol, 2000; Blackburn \& Duncan, 2001a; Blackburn et al., 2015).

\section{The Macroecology of Invasions}

Developments in macroecology have certainly influenced invasion biology over the last couple of decades, but biological invasions may also be informative for macroecologists. The reshuffling of the planet's biota by human agency has been argued to be a defining characteristic of a new geological epoch, the Anthropocene (Lewis \& Maslin, 2015). This reshuffling has broken biogeographic boundaries, resulting in novel geographic distributions for many species, and the prospect of novel ecosystems (Hobbs et al., 2009). An open question is the extent to which these reshufflings break or reconstitute the macroecological patterns exhibited by native species. Variation in the latitudinal gradient in species richness across previous geological epochs (Mannion et al., 2014), as well as apparent anthropogenic impacts on macroecological patterns in native species (Šizling et al., 2016; Faurby \& Araújo, 2017), suggests that such patterns may be quite plastic. Conversely, the fact that not all alien introductions result in established populations, coupled to niche conservatism (Wiens \& Graham, 2005), may cause alien species to recapitulate natural patterns. The outcomes are likely to depend on whether species are limited by the same processes in their alien and native ranges, and whether the key processes are short-term ecological interactions or longer term evolutionary selection. Either way, patterns expressed by alien species may inform about the drivers of those patterns in native species (Sax et al., 2005).

Currently, there are few studies of the macroecology of alien species, but at first glance those that do exist suggest that species are expressing similar patterns in their native and alien ranges. For example, alien species richness tends to increase from Polar regions towards the equator (Sax, 2001), reflecting the latitudinal gradient in native species richness (Rosenzweig, 1995); alien geographic range size tends to decrease from Polar regions towards the equator (Sax, 2001), a pattern known from native species as Rapaport's rule; larger geographic areas are home to more alien species (Blackburn et al., 2008, 2016; Dawson et al., 2017), reflecting the species-area relationship (Rosenzweig, 1995), and alien body masses also tend to 
decrease from Polar regions towards the equator (Blackburn et al., 2018), a pattern known from native species as Bergmann's rule. It would seem that alien species bend to whatever processes are determining the macroecology of native species.

However, returning the opening theme of this paper, it is necessary to consider the null expectation for these patterns. For aliens, one needs to address the possibility that patterns of occurrence are a simple consequence of patterns of introduction, without the intervention of natural drivers. A good example is provided by Bergmann's rule in alien birds (Blackburn et al., 2018). Alien bird species exhibit Bergmann's rule: the mean body mass of bird species with established alien populations in a given latitudinal band increases with latitude, falling in the range $50-100 \mathrm{~g}$ in the tropical zone but increasing to an average of over $700 \mathrm{~g}$ in some high latitude regions (Figure 1). There is a close match between the spatial body mass variation shown by aliens (Figure 1) and by natives (Olson et al., 2009). However, the great majority of spatial variation in alien body masses can be accounted for by the fact that people have tended to introduce smaller-bodied bird species to lower latitudes, and larger-bodied bird species to higher latitudes (Figure 1). Latitudinal variation in establishment success and subsequent range spread have barely modified that pattern. Thus, the fact that alien birds exhibit Bergmann's rule is more or less completely down to human actions in introducing different species to different latitudes. Where humans have introduced bird species to can also explain spatial variation in their species richness (Blackburn et al., 2008, 2016; Dyer et al., 2017) and geographic range size (Dyer et al., in prep.). Whether the same is true for macroecological patterns in other taxa is unclear, as unfortunately Aves is more or less the only group for which there is widespread information on where species have been introduced. Aliens certainly have the potential to inform on the drivers of ecological patterns in natives, but it may be more difficult to realise that potential than is generally appreciated.

\section{Conclusion}

Thirty years on from the foundation papers in macroecology, it is gratifying to reflect that the field has been so successful that it now has entire scientific journals, special interest groups and learned societies related to its study, not to mention this special issue of GEB. It is easy to forget the resistance it faced in its early years, such that Gaston \& Blackburn (1999) were moved to write about how "the emergence of macroecology has been [accompanied by] a 
barrage of criticism of this general approach to answering ecological questions...". At the time, the standard modus operandi in ecology was the small-scale, short-term experimental manipulation, which itself came to dominate as a response to an even earlier tendency to use patterns uncritically in support of ecological theory (Lawton, 1996). The power of experiments is undeniable, but there is unquestionably also a place for approaches that exploit effects measured over the spatial and temporal scales relevant to ecosystems. The continued growth of the field of macroecology alone would prove it. Yet, more than that, macroecology has informed developments in other research areas too. Invasion biology would not have developed in the direction it has without the application of insights gained from macroecological experience. I believe that the effects of those insights have been positive - and given that I've spent much of my career trying to deal with bias, I hope that I'm not at this point falling prey to it myself.

\section{Acknowledgements}

I would like to thank Brian McGill, Maria Dornelas and Richard Field for inviting me to be part of this special issue, and the numerous people who have shared their ideas and time with me over the years I have been studying macroecology and invasion biology, especially (in alphabetical order) Phill Cassey, Steven Chown, Richard Duncan, Ellie Dyer, Kevin Gaston, Richard Gregory, Paul Harvey, Kate Jones, John Lawton, Julie Lockwood, Ian Owens, Mark Pagel, Petr Pyšek, Dave Richardson, Helen Roy, Gavin Thomas, and Craig White. 


\section{References}

Blackburn, T.M. (2004) Method in macroecology. Basic and Applied Ecology, 5, 401-412.

Blackburn, T.M., Cassey, P. \& Lockwood, J.L. (2008) The island biogeography of exotic bird species. Global Ecology and Biogeography, 17, 246-251.

Blackburn, T.M., Delean, S., Pyšek, P. \& Cassey, P. (2016) On the island biogeography of aliens: a global analysis of the richness of plant and bird species on oceanic islands. Global Ecology and Biogeography, 25, 859-868.

Blackburn, T.M. \& Duncan, R.P. (2001a) Determinants of establishment success in introduced birds. Nature, 414, 195-197.

Blackburn, T.M. \& Duncan, R.P. (2001b) Establishment patterns of exotic birds are constrained by non-random patterns in introduction. Journal of Biogeography, 28, 927-939.

Blackburn, T.M., Dyer, E., Su, S. \& Cassey, P. (2015) Long after the event, or four things we (should) know about bird invasions. Journal of Ornithology, 156 s1, 15-25.

Blackburn, T.M. \& Gaston, K.J. (1998) Some methodological issues in macroecology. The American naturalist, 151, 68-83.

Blackburn, T.M., Harvey, P.H. \& Pagel, M.D. (1990) Species number, population density and body size relationships in natural communities. Journal of Animal Ecology, 59, 335345.

Blackburn, T.M., Lockwood, J.L. \& Cassey, P. (2009) Avian invasions. The ecology and evolution of exotic birds., Oxford University Press, Oxford.

Blackburn, T.M., Pyšek, P., Bacher, S., Carlton, J.T., Duncan, R.P., Jarošík, V., Wilson, J.R.U. \& Richardson, D.M. (2011) A proposed unified framework for biological invasions. Trends in Ecology \& Evolution, 26, 333-339.

Blackburn, T.M., Redding, D.W. \& Dyer, E.E. (2018) Bergmann's Rule in alien birds. Ecography.

Blackburn, T.M., Scrivens, S.L., Heinrich, S. \& Cassey, P. (2017) Patterns of selectivity in introductions of mammal species worldwide. NeoBiota, 33, 33-51.

Brown, J.H. \& Maurer, B.A. (1987) Evolution of species assemblages: effects of energetic constraints and species dynamics on the diversification of the American avifauna. American Naturalist, 130, 1-17. 
Cassey, P., Blackburn, T.M., Jones, K.E. \& Lockwood, J.L. (2004) Mistakes in the analysis of exotic species establishment: source pool designation and correlates of introduction success among parrots (Aves: Psittaciformes) of the world. Journal of Biogeography, 31, 277-284.

Cassey, P., Delean, S., Lockwood, J.L., Sadowski, J.S. \& Blackburn, T.M. (2018) Dissecting the null model for biological invasions: A meta-analysis of the propagule pressure effect. PLOS Biology, 16, e2005987.

Dawson, W., Moser, D., van Kleunen, M., Kreft, H., Pergl, J., Pyšek, P., Weigelt, P., Winter, M., Lenzner, B., Blackburn, T.M., Dyer, E.E., Cassey, P., Scrivens, S.L., Economo, E.P., Guénard, B., Capinha, C., Seebens, H., García-Díaz, P., Nentwig, W., García-Berthou, E., Casal, C., Mandrak, N.E., Fuller, P., Meyer, C. \& Essl, F. (2017) Global hotspots and correlates of alien species richness across taxonomic groups. Nature Ecology \& Evolution, 1, 0186.

Diamond, J. (1986) Overview: laboratory experiments, field experiments, and natural experiments. Community Ecology (ed. by J. Diamond) and T.J. Case), pp. 3-22. Harper Row, New York.

Drake, J.A., di Castri, F., Groves, R.H., Kruger, F.J., Rejmánek, M. \& Williamson, M. (1989) Biological invasions. A global perspective., John Wiley \& Sons, Chichester, UK.

Dyer, E.E., Cassey, P., Redding, D.W., Collen, B., Franks, V., Gaston, K.J., Jones, K.E., Kark, S., Orme, C.D.L. \& Blackburn, T.M. (2017) The global distribution and drivers of alien bird species richness. PLoS Biology, 15, e2000942.

Elton, C. (1958) The ecology of invasions by animals and plants., Methuen, London.

Faurby, S. \& Araújo, M.B. (2017) Anthropogenic impacts weaken Bergmann's rule. Ecography, 40, 683-684.

Gaston, K.J. \& Blackburn, T.M. (1999) A critique for macroecology. Oikos, 84, 353-368.

Goodwin, B.J., McAllister, A.J. \& Fahrig, L. (1999) Predicting invasiveness of plant species based on biological information. Conservation Biology, 13, 422-426.

Hobbs, R.J., Higgs, E. \& Harris, J.A. (2009) Novel ecosystems: implications for conservation and restoration. Trends in Ecology \& Evolution, 24, 599-605.

van Kleunen, M., Dawson, W., Schlaepfer, D., Jeschke, J.M. \& Fischer, M. (2010) Are invaders different? A conceptual framework of comparative approaches for assessing determinants of invasiveness. Ecology Letters, 13, 947-958. 
Kolar, C.S. \& Lodge, D.M. (2001) Progress in invasion biology: predicting invaders. Trends in Ecology and Evolution, 16, 199-204.

Lawton, J.H. (1996) Patterns in ecology. Oikos, 75, 145-147.

Lewis, S.L. \& Maslin, M.A. (2015) Defining the Anthropocene. Nature, 519, 171-180.

Lockwood, J.L. (1999) Using taxonomy to predict success among introduced avifauna:

Relative importance of transport and establishment. Conservation Biology, 13, 560567.

Lockwood, J.L., Cassey, P. \& Blackburn, T. (2005) The role of propagule pressure in explaining species invasions. Trends in Ecology \& Evolution, 20, 223-228.

Mannion, P.D., Upchurch, P., Benson, R.B.J. \& Goswami, A. (2014) The latitudinal biodiversity gradient through deep time. Trends in Ecology \& Evolution, 29, 42-50.

Olson, V.A., Davies, R.G., Orme, C.D.L., Thomas, G.H., Meiri, S., Blackburn, T.M., Gaston, K.J., Owens, I.P.F. \& Bennett, P.M. (2009) Global biogeography and ecology of body size in birds. Ecology Letters, 12, 249-259.

Richardson, D.M., Pyšek, P. \& Carlton, J. (2011) A compendium of essential concepts and terminology in invasion ecology. Fifty years of invasion ecology. The legacy of Charles Elton. (ed. by D.M. Richardson), pp. 409-420. John Wiley \& Sons Ltd, Oxford.

Richardson, D.M., Rouget, M. \& Rejmánek, M. (2004) Using natural experiments in the study of alien tree invasions. Experimental approaches to conservation biology. (ed. by M.S. Gordon) and S.M. Bartol), pp. 180-200. University of California Press.

Rosenzweig, M.L. (1995) Species diversity in space and time., Cambridge University Press, Cambridge.

Sax, D.F. (2001) Latitudinal gradients and geographic ranges of exotic species: implications for biogeography. Journal of Biogeography, 28, 139-150.

Sax, D.F., Gaines, S.D. \& Stachowicz, J.J. (2005) Exotic species: a source of insight into ecology, evolution, and biogeography, Academic Press, Sunderland, Massachussets.

Simberloff, D. (2009) The role of propagule pressure in biological invasions. The Annual Review of Ecology, Evolution, and Systematics, 40, 81-102.

Šizling, A.L., Pokorný, P., Juřičková, L., Horáčková, J., Abraham, V., Šizlingová, E., Ložek, V., Tjørve, E., Tjørve, K.M.C. \& Kunin, W. (2016) Can people change the ecological rules that appear general across space? Global Ecology and Biogeography, 25, 1072-1084. 
Sol, D. (2000) Are islands more susceptible to be invaded than continents? Birds say no. Ecography, 23, 687-692.

Sol, D., Maspons, J., Vall-Ilosera, M., Bartomeus, I., García-Peña, G.E., Piñol, J. \& Freckleton, R.P. (2012) Unraveling the life history of successful invaders. Science, 337, 580-583. Tingley, R., Romagosa, C.M., Kraus, F., Bickford, D., Phillips, B.L. \& Shine, R. (2010) The frog filter: amphibian introduction bias driven by taxonomy, body size and biogeography. Global Ecology and Biogeography, 19, 496-503.

Wiens, J.J. \& Graham, C.H. (2005) Niche conservatism: integrating rvolution, rcology, and conservation biology. Annual Review of Ecology, Evolution, and Systematics, 36, 519539.

Williamson, M. (1996) Biological invasions., Chapman and Hall, London.

Williamson, M. \& Brown, K.C. (1986) The analysis and modelling of British invasions. Philosophical Transactions of the Royal Society B: Biological Sciences, 314, 505-522. Williamson, M.H., Kornberg, H., Holdgate, M.W., Gray, A.J. \& Conway, G.R. (1986) Preface: The British Contribution to the SCOPE Programme on the Ecology of Biological Invasions. Philosophical Transactions of the Royal Society B: Biological Sciences, 314, 503-504.

\section{BioSketch}

Tim Blackburn is an ecologist with a background in macroecology. His current research is largely focused on understanding the processes driving human-mediated biological invasions, using birds as a model taxon.

\section{Data Availability Statement}

This study includes no data. 
Figure 1. The relationship between mean $\log _{10}$ body mass (grammes, \pm standard deviation) of species in a latitudinal band and the latitudinal midpoint of that band (degrees), for introduced (open circles) and established (filled circles) alien bird species. From Blackburn et al. (2018). 